05

\title{
Влияние пористости и размера зерна на фазовый состав и механические свойства керамики на основе диоксида циркония
}

\author{
(С) Н.Л. Савченко ${ }^{1}$, Т.Ю. Саблина ${ }^{1}$, И.Н. Севостьянова ${ }^{1}$, \\ А.Г. Бурлаченко ${ }^{1}$, С.П. Буякова ${ }^{1,2}$, С.Н. Кульков ${ }^{1,2, \uparrow}$ \\ ${ }^{1}$ Институт фризики прочности и материаловедения СО РАН, Томск, Россия \\ ${ }^{2}$ Национальный исследовательский Томский государственный \\ университет, Томск, Россия \\ ฯE-mail: kulkov@ms.tsc.ru
}

Поступило в Редакцию 4 апреля 2018 г.

Исследована керамика $\mathrm{ZrO}_{2}(\mathrm{Y})$ с введенными частицами порообразователя сверхвысокомолекулярного полиэтилена. Показано, что пористость образцов после спекания изменялась от 2 до $42 \mathrm{vol} \%$, а размер зерна - от 0.5 до $1.55 \mu \mathrm{m}$ в зависимости от режимов спекания. Прочность материалов с минимальной пористостью составляла $3000 \pm 200 \mathrm{MPa}$, а для материалов с максимальной пористостью $-100 \pm 20 \mathrm{MPa}$, при этом она не зависела от размера зерна. Показано, что в материале реализуется мартенситное превращение из тетрагональной фазы в моноклинную, связанное с механическими напряжениями, которое не влияет на макропрочность материала. Основным фактором, обусловливающим такое превращение в пористом материале, являются внутренние микронапряжения, уменьшающиеся с ростом пористости и увеличением размера зерна керамики.

DOI: $10.21883 /$ PJTF.2018.15.46436.17316

Механические свойства пористых керамик в последнее время вызывают повышенный интерес, связанный с переходами между упругим, хрупким и „ячеистым“ поведением при нагружении в зависимости от морфологического строения порового пространства [1-4]. Кроме морфологического строения порового пространства на механические характеристики в керамиках на основе диоксида циркония влияют фазовые превращения, в частности тетрагонально-моноклинный переход [5] при нагружении пористого тела, однако подобные исследования не 
проводились, хотя известно [6,7], что пористость может влиять на такие превращения.

В работах $[5,8]$ установлено, что превращение тетрагональной фазы в моноклинную под действием напряжений определяется тремя основными факторами: 1) содержанием растворенного стабилизатора, уменьшение количества которого приводит к спонтанному превращению в моноклинную фазу; 2) размером зерна, причем при его увеличении выше некоторого критического значения происходит спонтанное превращение в моноклинную фазу; 3) внутренними напряжениями, стабилизирующими тетрагональную фазу. Поэтому соотношение этих трех факторов существенно влияет на реализацию механизмов упрочнения.

При получении высокопористой керамики на основе диоксида циркония, способной испытывать мартенситное превращение, основная проблема заключается в том, что, как правило, не удается создать керамику одновременно с большой пористостью и необходимым размером зерна тетрагональной фазы, при котором может реализоваться механизм мартенситного превращения под нагрузкой. Керамику с широким диапазоном размеров зерна и пористости можно получить при высокотемпературном спекании с введением порообразующих добавок.

Цель настоящей работы - исследовать влияние размера зерна и пористости на фазовый состав и прочностные свойства керамики на основе стабилизированного иттрием диоксида циркония.

Для получения пористых образцов использовались смеси исходного порошка $\mathrm{ZrO}_{2}-5.5$ wt.\% $\mathrm{Y}_{2} \mathrm{O}_{3}\left(\mathrm{ZrO}_{2}(\mathrm{Y})\right)$ марки ЦрОИ-5.5 в состоянии поставки и порообразователя - сферических частиц сверхвысокомолекулярного полиэтилена с молекулярной массой $M=0.5 \cdot 10^{6} \mathrm{~g} / \mathrm{mol}$ и средним размером частиц $45 \mu \mathrm{m}$ до $60 \mathrm{vol} . \%$. После смешивания порошков с порообразователем проводилось их прессование в виде цилиндрических образцов диаметром $9 \mathrm{~mm}$ и высотой $11 \mathrm{~mm}$ на гидравлическом прессе в стальной пресс-форме. Для получения керамики, различающейся по величине среднего размера зерна, спекание образцов на воздухе осуществлялось при температурах 1500 и $1600^{\circ} \mathrm{C}$ с изотермической выдержкой в течение $1,3,5$ h. Скорость нагрева и охлаждения составляла $4^{\circ} \mathrm{C} / \mathrm{min}$. Плотность образцов определялась геометрически по пяти образцам, относительная погрешность составляла $5 \%$.

Фазовый состав керамических образцов определялся по дифрактограммам, полученным на рентгеновском дифрактометре с фильтрованным $\mathrm{Cu} K_{\alpha}$-излучением в интервале углов $2 \theta=20-80^{\circ}$. Структура

Письма в ЖТФ, 2018, том 44, вып. 15 


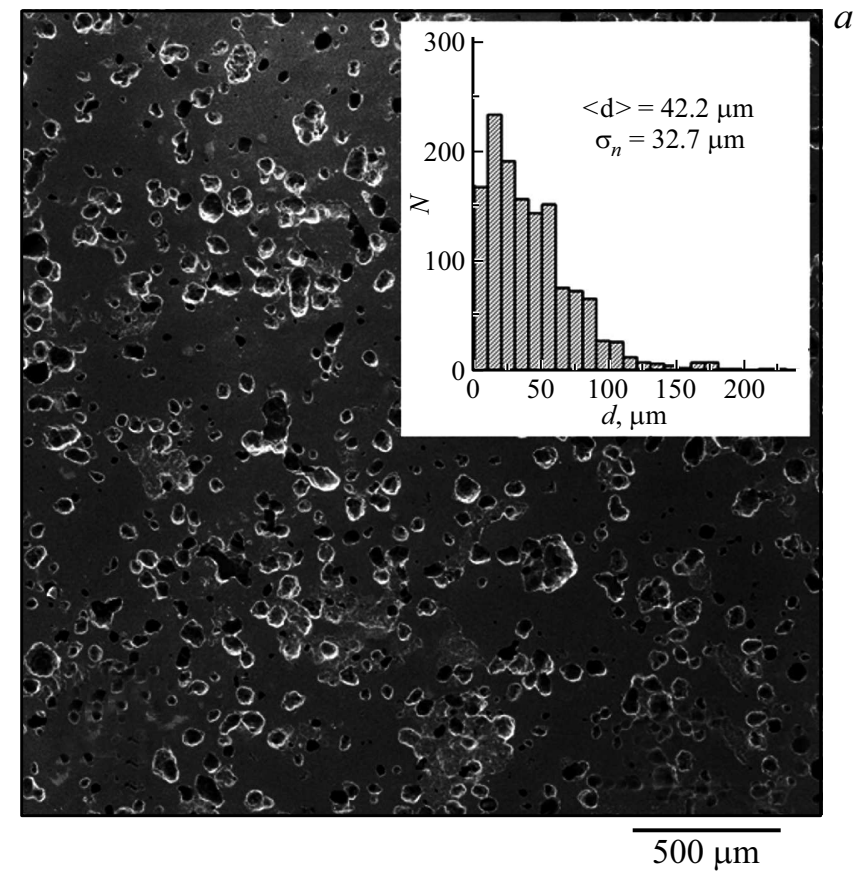

Рис. 1. Типичная поровая $(a)$ и зеренная $(b)$ структуры спеченной керамики с пористостью $30 \mathrm{vol} . \%$. На вставках - распределение по размерам пор и зерен керамики, спеченной при температуре $1600^{\circ} \mathrm{C}$ в течение $1 \mathrm{~h}$.

образцов изучалась на растровом электронном микроскопе VEGA TESCAN. Размер зерна $(d)$ определялся по изображениям термически травленых полированных поверхностей образцов с использованием программы ImageJ [9]. Механические испытания образцов на осевое сжатие проводились на универсальной испытательной машине Инстрон-1185 при скорости нагружения $0.1 \mathrm{~mm} / \mathrm{min}$.

На рис. 1 приведена типичная структура пористой керамики после спекания. Пористость после спекания составляла от 2 до 42 vol.\% в зависимости от количества введенного порообразователя, температуры и времени спекания. При этом средний размер пор (вставка на рис. 1, $a$ ) слабо зависел от режимов спекания и изменялся от 40 до $43 \mu \mathrm{m}$.

Письма в ЖТФ, 2018, том 44, вып. 15 


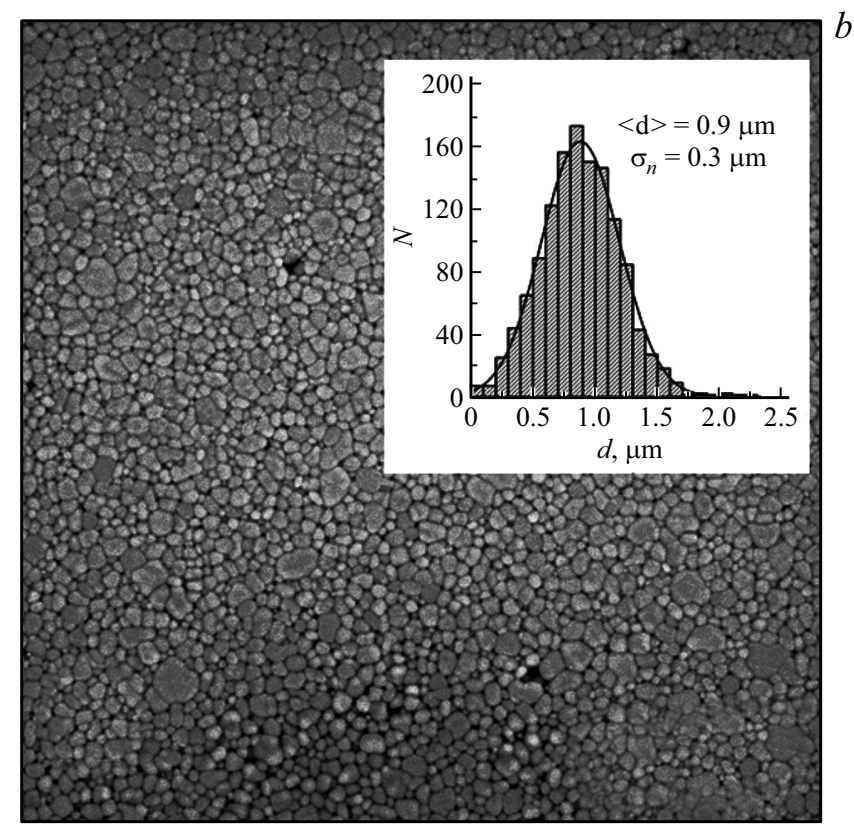

$10 \mu \mathrm{m}$

Рис. 1 (продолжение).

В зависимости от температуры и времени выдержки при спекании средний размер зерна изменялся от $0.5 \mu \mathrm{m}\left(1500^{\circ} \mathrm{C}, 1 \mathrm{~h}\right)$ до $1.55 \mu \mathrm{m}$ $\left(1600^{\circ} \mathrm{C}, 5 \mathrm{~h}\right)$ (вставка на рис. $\left.1, b\right)$.

На основании рентгенофазового анализа установлено, что после спекания образцы находились в двухфазном (кубическом и тетрагональном) или трехфазном (кубическом, тетрагональном и моноклинном) состояниях. При этом содержание кубической фазы во всех образцах составляло $18-20 \%$, что согласуется с данными [10], и не зависело от размера зерна и пористости. При пористости до 7 vol.\% моноклинной фазы на полированной поверхности образцов не наблюдалось для всех размеров зерна. С увеличением пористости до 15 vol.\% моноклинная фаза после спекания зафиксирована только в образцах со средним размером зерна $1.55 \mu \mathrm{m}$. Дальнейшее повышение пористости до 42 vol.\%

Письма в ЖТФ, 2018, том 44, вып. 15 


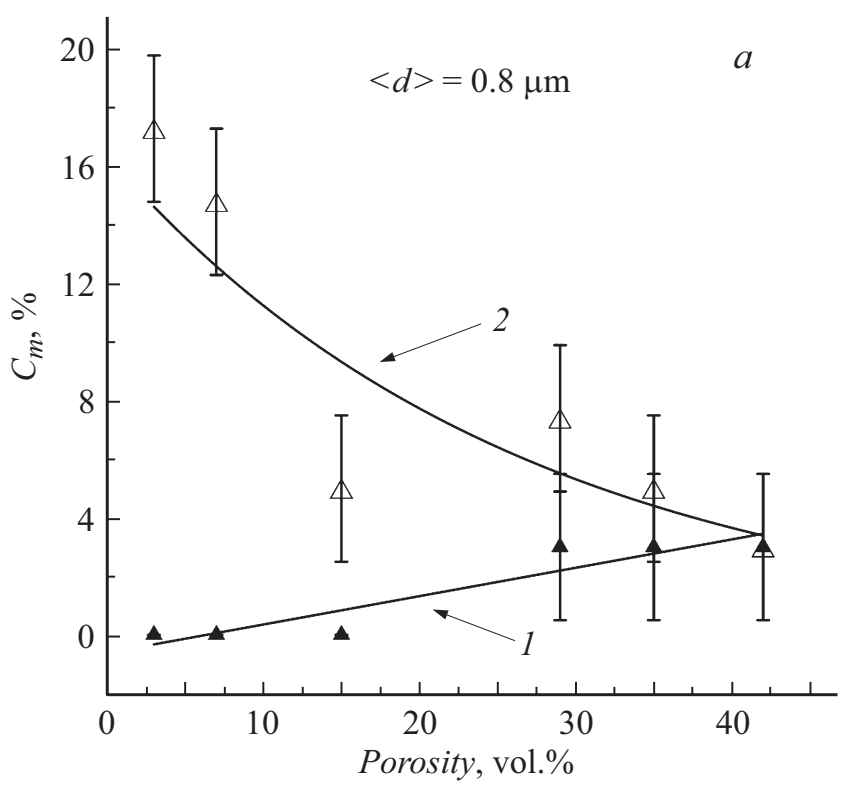

Рис. 2. $a-$ зависимость содержания моноклинной фазы на полированной поверхности (1) и на поверхности разрушения (2) от объема порового пространства керамики, $b-$ зависимость приращения количества моноклинной фазы на поверхности разрушения после испытания на сжатие от среднего размера зерна керамики при различной пористости (указана на рисунке).

приводит к образованию моноклинной фазы в керамиках с размером зерна выше $0.7 \mu \mathrm{m}$, причем ее количество возрастает как с увеличением размера зерна, так и с увеличением пористости (см. таблицу).

Проведенные механические испытания показали, что значения предела прочности при сжатии для материалов с минимальной пористостью составляли $3000 \pm 200 \mathrm{MPa}$, а для материалов с максимальной пористостью - $100 \pm 20 \mathrm{MPa}$, причем они не зависели от среднего размера зерен $\mathrm{ZrO}_{2}(\mathrm{Y})$.

После испытаний на сжатие в образцах керамики на поверхности разрушения регистрировалось либо появление, либо увеличение содержания моноклинной фазы (см. таблицу). Однако изменение фазового состава на поверхности разрушения образцов не сказывается на их

Письма в ЖТФ, 2018, том 44, вып. 15 


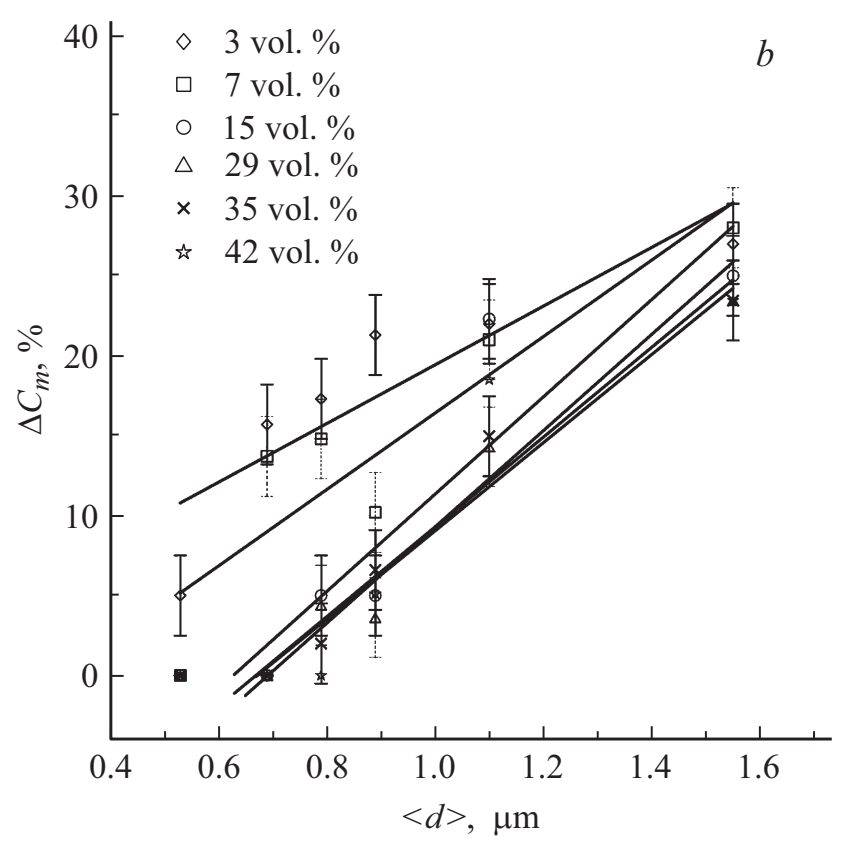

Рис. 2 (продолжение).

прочности. По-видимому, вследствие сложной структуры таких материалов с распределенными по всему объему крупными порами трансформационный механизм упрочнения в пористом диоксиде циркония реализуется иначе, чем в случае плотного материала.

Следует отметить, что керамика со средним размером зерна менее $0.7 \mu \mathrm{m}$ при пористости выше 15 vol.\% не претерпевала трансформационного превращения под нагрузкой (см. таблицу). Оценка количества моноклинной фазы диоксида циркония, сформировавшегося в образцах на поверхности разрушения, показала, что доля тетрагональной фазы, превращенной в моноклинную, при фиксированном среднем размере зерна уменьшается с ростом пористости (рис. 2,a). При фиксированном значении пористости доля превращенной тетрагональной фазы увеличивается с ростом размера зерен (рис. 2,b). Также из рис. $2, b$ видно, что образцы керамики с большим средним размером

Письма в ЖТФ, 2018, том 44, вып. 15 
Содержание моноклинной фазы на полированной поверхности спеченной керамики и на поверхности разрушения в зависимости от размера зерна и пористости

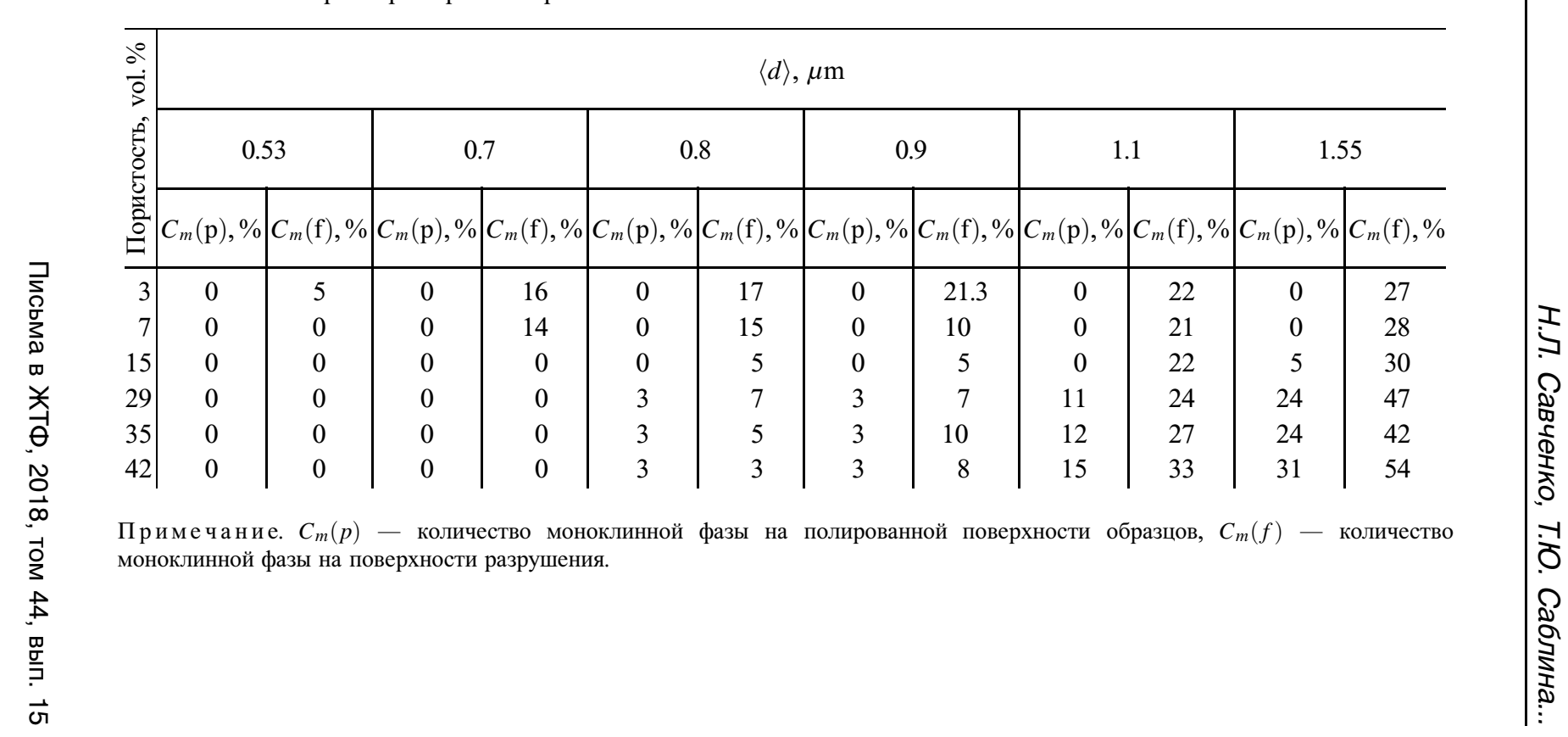




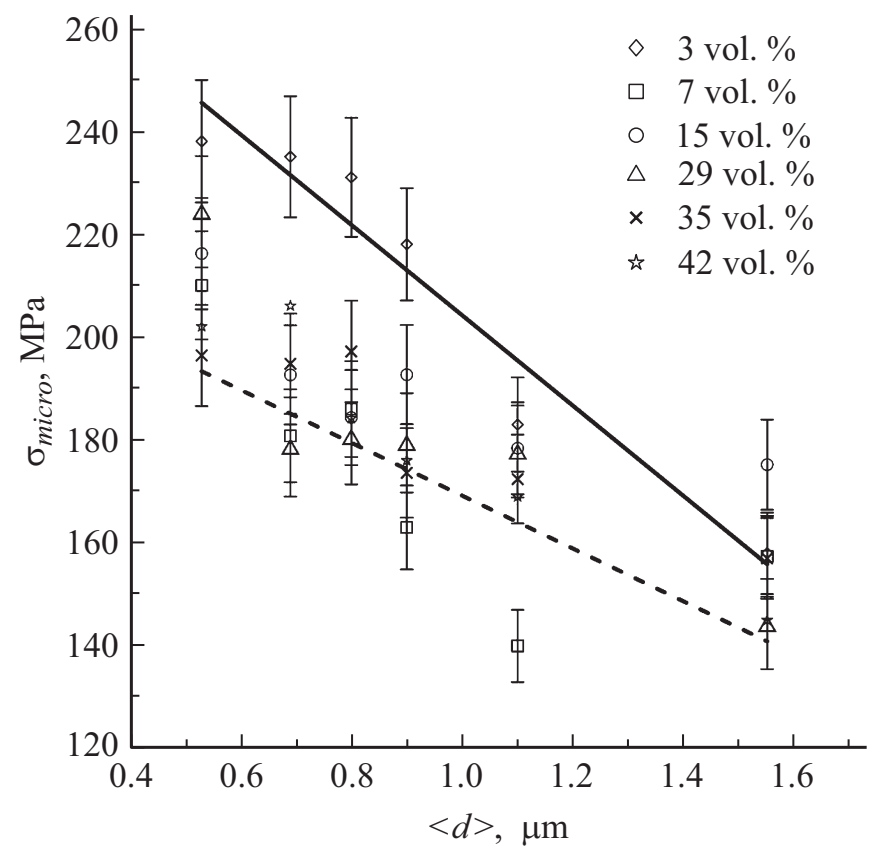

Рис. 3. Зависимость микронапряжений от среднего размера зерна пористой керамики при различной пористости (указана на рисунке).

зерна, равным $1.55 \mu \mathrm{m}$, имели высокую долю приращения моноклинной фазы (около 23\%) даже при максимальной пористости (42 vol.\%) (см. таблицу).

По данным рентгеноструктурного анализа были оценены величины микронапряжений (напряжения второго рода в соответствии с [11]). Результаты показаны на рис. 3 , из которого следует, что как увеличение среднего размера зерна, так и увеличение пористости приводят к заметному понижению микронапряжений. По-видимому, увеличение пористости в образцах ведет к образованию свободных поверхностей, что сопровождается уменьшением локальных напряжений.

Таким образом, показано, что в пористой керамике возможно трансформационное превращение, связанное с механическими напряжениями, которое, однако, не влияет на макропрочность материала.

Письма в ЖТФ, 2018, том 44, вып. 15 
При этом основным фактором, обусловливающим такое превращение в пористом материале, являются внутренние микронапряжения (напряжения второго рода), уменьшающиеся с ростом пористости и увеличением размера зерна керамики.

Работа выполнена в рамках Программы фундаментальных научных исследований государственных академий наук на 2013-2020 гг. (направление III.23).

Авторы выражают благодарность сотрудникам ИФПМ СО РАН Л.М. Молчуновой и Л.Н. Рыжовой за помощь при подготовке образцов.

\section{Список литературы}

[1] Meille S., Lombardi M., Chevalier J., Montanaro L. // J. Eur. Ceram. Soc. 2012. V. 32. N 15. P. 3959-3967.

[2] Григорьев М.В., Савченко Н.Л., Буякова С.П., Кульков С.Н. // Письма в ЖТФ. 2017. Т. 43. В. 15. С. 79-86.

[3] Савченко Н.Л., Саблина Т.Ю., Севостьянова И.Н., Буякова С.П., Кульков С.Н. // Изв. вузов. Физика. 2015. № 11. С. 56-60.

[4] Abad-Javier M.E., Cajero-Juarez M., Contreras García M.E. // Epitöanyag: J. Silicate Based Composite Mater. 2016. V. 68. N 3. P. 124-128.

[5] Evans A.G., Cannon R.M. // Acta Met. 1986. V. 34. N 5. P. 761-800.

[6] Gain A.K., Song H.-Y., Lee B.T. // Scripta Mater. 2006. V. 504. N 12. P. 20812085.

[7] Alao A.-R., Yin L. // J. Mater. Sci. Technol. 2016. V. 32. N 5. P. 402-410.

[8] Lange F.F. // J. Mater. Sci. 1982. V. 17. N 1. P. 240-246.

[9] http://www.imagej.ru (сообщество разработчиков и пользователей ImageJ).

[10] Matsui K., Horikoshi H., Ohmichi N., Ohgai M., Yoshida H., Ikuhara Y. // J. Am. Ceram. Soc. 2003. V. 86. N 8. P. 1401-1408.

[11] Уманский Я.С., Скаков Ю.А., Иванов А.Н., Расторгуев А.Н. Кристаллография, рентгенография и электронная микроскопия. М.: Металлургия, 1982. $632 \mathrm{c}$. 